\title{
The Effect of Material Behaviour on the Surface Roughness during Machining of H13 Tool Steel
}

\author{
Anoop K, Kalyan Chakraborty
}

\begin{abstract}
The aim of the present study is to know the effect of material properties on surface roughness during dry turning of $\mathrm{H13}$ tool steel. Machining was performed using Tungaloy made carbide insert. Chip reduction coefficient (CRC) and surface roughness values (Ra) were experimentally determined. Twenty seven experiments were conducted following $3^{3}$ factorial design. Subsequently, chip samples were examined under scanning electron microscope. Surface roughness values were found to be influenced by strain hardening and strain rate hardening of the material depending upon the values of speed, feed and depth of cut (d.o.c). Surface quality improves because of strain rate hardening at higher cutting speed.

Keywords: tool steel, chip reduction coefficient, factorial design, strain rate hardening
\end{abstract}

\section{INTRODUCTION}

H13 tool steel is hot work tool steel alloyed with mainly chromium, molybdenum and vanadium. Carbon content may be in the lower range and medium range. These alloying elements are carbide formers to impart high thermal resistance and hot hardness. H13 tool steels are used for extrusion molds, die casting molds and steel forging applications. The hardness of $\mathrm{H} 13$ tool steel is greater than 45 HRC. H13 tool steel is usually processed by grinding to obtain desired surface finish. Hard turning of H13 tool steel can be preferable to avoid detrimental effect of grinding. Hard turning is defined as a turning process for machining parts with hardness exceeding 45 HRC. These materials are also used for aerospace and automobile applications. Surface quality of the machined item is one of the important considerations. Material behaviour during machining affects the surface quality. Machining induces deformation on the work material. Machining chip is a deformed part of the work material. Strain hardening and strain rate hardening of the work material act to influence the surface finish during machining. Č.E.P Robert et al. [1] found the influence of feed rate on the quality of the machined surface. Cutting tool HURCO VMXt30 was used to carry out the experiment for various speeds and feed per tooth. Testing was carried out with two most common materials in the steel grades 1.1191 (12 050) and 1.2343 (19 552). They had chosen two ordinary parameters $\left(\mathrm{R}_{\mathrm{a}}\right.$ and $\left.\mathrm{R}_{\mathrm{z}}\right)$ and confirmed that the roughness parameters are decreasing with increasing cutting speed for steel grade 1.1191 (12 050). It was observed that the surface roughness parameters are increasing with higher feed per tooth. They also found that the surface roughness parameters are decreasing at increasing cutting speed for steel grade 1.2343 (19 552).

Revised Manuscript Received on May 15, 2020.

*Correspondence Author.

Anoop K, M. Tech. Student, M. E. Department, N.I.T. Silchar, Assam, India.

Kalyan Chakraborty*, M.E. Department, N.I.T. Silchar, Assam, India. E-mail: kalyan.ch2013@gmail.com

(C) The Authors. Published by Blue Eyes Intelligence Engineering and Sciences Publication (BEIESP). This is an open access article under the CC BY-NC-ND license (http://creativecommons.org/licenses/by-nc-nd/4.0/)
Amritpal Singh et al. [2] described the effects of different process parameters such as cutting speed, cutting depth and feed rate on response parameters such as surface roughness, material removal rate and chip reduction coefficient. Main cutting parameters which affect the turning operation were discussed. There are essentially three main cutting parameters, which are feed rate, speed and depth of cut. Key performance parameters included chip thickness, material removal rate and surface roughness. They provided the summary of the hard turning of the various hardened steels. They observed that hard turning provides a range of possible benefits over grinding, including shorter set-up times, shorter equipment costs, versatility in process and design, and the avoidance of the use of cutting fluid. They found that Surface roughness and material removal rate were output parameters which were greatly influenced by cutting parameters like hardness of the work piece, tool material and tool vibrations. It was found that feed rate is the most significant factor preceded by cutting depth in the case of surface roughness and cutting speed is the most significant factor for tool wear. They also observed that feed and cutting depth are important parameters for increasing the material removal rate. They observed that the profitability of the closed tolerance products can be improved by choosing the feed rate, the cutting depth and the cutting speed during hard turning. Tugrul "Ozel et al. [3] studied the effects of cutting edge geometry, hardness of the workpiece, feed rate and cutting speed on surface roughness and resulting forces during hard turning of the AISI H13 steel. Cubic boron nitride inserts with two separate edge preparations were selected for hard turning of AISI H13 steel bars . Four-factor (hardness, edge geometry, feed rate and cutting speed) two-level factorial experiments were performed and statistical analysis of variance was performed. The material used was AISI H13 hot work tool steel. CBN inserts with two distinct representative forms of edge preparation were selected. A four-factor two-level factorial design was used to assess the effects of cutting edge geometry, hardness of the workpiece, feed rate and cutting speed on surface roughness and on resulting forces in the hard turning finish of AISI H13 steel. Longitudinal turning was carried out on a rigid, high-precision CNC lathe at a constant depth of cut of $0.254 \mathrm{~mm}$. The results showed that the impact of cutting edge geometry on the surface is surprisingly important. The cutting forces were affected not only by cutting conditions, but also by cutting edge geometry and surface hardness of the workpiece. The effects of the two-factor interactions of edge geometry and workpiece hardness, edge geometry and feed rate, and cutting speed and feed rate also tend to be significant.

R. Ferreira et al. [4] presented an experimental investigation of AISI H13 steel turning with ceramic tools. The flank were

Blue Eyes Intelligence Engineering

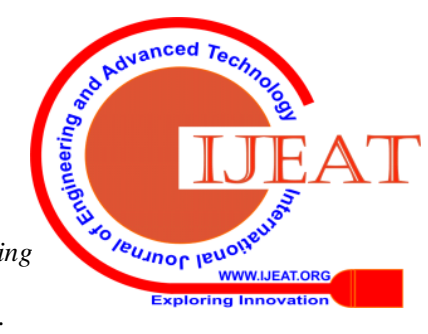

\& Sciences Publication

(C) Copyright: All rights reserved. 
of ceramic tools and their effect on the surface quality of turned AISI H13 steel were investigated. The effect of tool geometry, the application of wiper technology and the configuration of the tool nose were evaluated. Turning tests were carried out using the 'Kingsbury MHP 50' CNC lathe . They used DCLNL $2020 \mathrm{~K} 12$ (ISO) tool holder and ceramic tools. The workpiece used in the experiment was AISI H13 tool steel in the form of bars. Flank wear was found to be highly affected by cutting speed. Minor impact of the type of tool was noticed on the flank wear. As far as surface roughness is concerned, no consistent pattern has been observed depending on the tool wear, for both conventional and wiper tools. The effect of tool wear on surface roughness was evaluated with Pearson's r correlation coefficient. The study showed that there was no consistent pattern for the obtained values.

\section{EXPERIMENTAL PROCEDURE}

Central lathe was employed to machine the work piece. This lathe is having the speed range of $45 \mathrm{rpm}$ to $1000 \mathrm{rpm}$ and feed range of $0.06 \mathrm{~mm} / \mathrm{rev}$ to $1.72 \mathrm{~mm} / \mathrm{rev}$. Tungaloy made tool was used for machining of the work piece. Used Tool holder specification was ASBNR $25 \times 25$ M12-. AISI H13 tool steel round bar was selected as work material for dry turning operation. The chip samples were examined under scanning electron microscope (SEM). Surfaces of the chip were considered during SEM examination. by TM4000 scanning electron microscope. The surface roughness was measured using the $3 \mathrm{D}$ optical surface profilometer. $\mathrm{R}_{\mathrm{a}}$ data is shown in appendix.

A Input process parameters for machining of H13 tool steel Input process parameter values are shown in table 1

Table 1 Input process parameter for $\mathrm{H} 13$ steel

\begin{tabular}{|c|c|c|c|}
\hline Factors & Level 1 & Level2 & Level3 \\
\hline Code & -1 & 0 & 1 \\
\hline $\begin{array}{c}\text { Speed } \\
(\mathrm{m} / \mathrm{min})\end{array}$ & 64 & 80 & 100 \\
\hline $\begin{array}{c}\text { Feed } \\
(\mathrm{mm} / \mathrm{rev})\end{array}$ & 0.07 & 0.1 & 0.14 \\
\hline $\begin{array}{c}\text { D.O.C } \\
(\mathrm{mm})\end{array}$ & 0.67 & 1 & 1.5 \\
\hline
\end{tabular}

Lowest speed parameter level can be obtained by

$\operatorname{Code}(v, f, d)=\frac{\log (v, f, d)-\log (v, f, d) m}{\log (v, f, d) \max -\log (v, f, d) m}$

where,

Code $(v, f, d)=$ Values for various codes with reference to speed,feed and d.o.c.

$(v, f, d) \mathrm{m}=$ cutting speed, feed and doc at moderate level.

$(v, f, d) \max =$ cutting speed, feed and doc at highest level.

Based on the above given input process parameters, $3^{3}$ factorial design of experiment was performed which provided 27 different combinations. After the machining operation from 27 different experiments, one chip from each experimental sample was selected and its length and weight were measured respectively. After the measurement, uncut chip thickness, formed chip thickness and chip reduction coefficient were calculated from the theoretical relations. Those theoretical relations are shown below:

Uncut Chip Thickness, $\mathrm{t}_{1}=\mathrm{f} \sin \boldsymbol{\Phi}$

where,

$\mathrm{f}=$ Feed $(\mathrm{mm} / \mathrm{rev})$

$\boldsymbol{\Phi}=$ Principal Cutting edge angle (in degree)

Cut chip thickness,$t 2=\frac{W}{\rho w l}$

where,

$W=$ Weight of a chip (gm)

$\boldsymbol{\rho}=$ Density of the steel $\left(0.008 \mathrm{gm} / \mathrm{mm}^{3}\right)$

$l=$ Length of a chip (mm)

$w=$ Width of a chip (mm)

width of chip, $w=\frac{d}{\cos \Phi}$

where,

$d=$ Depth of cut (mm)

Chip reduction coefficient, $\xi=\left(\mathrm{t}_{2} / \mathrm{t}_{1}\right)$

where

$\mathrm{t}_{1}=$ Uncut chip thickness.

$\mathrm{t}_{2}=$ Formed chip thickness.

\section{RESULTS AND DISCUSSIONS}

\section{A. On chip reduction coefficient (CRC)}

Fig. 1 , Fig. 2 and Fig. 3 show increased values of CRC at low speed for all feed and doc. This is attributed to the thermal softening effect at low speed . Evidence of thermal softening is very much available at the under surface of the chip at lower cutting speed as seen in Fig. 4(a) and Fig. 4( b). Used tool insert was having designed chip breaking shape and chip breaking effect was more pronounced at lowest cutting speed. These can be seen in Fig. 5 and Fig. 6.

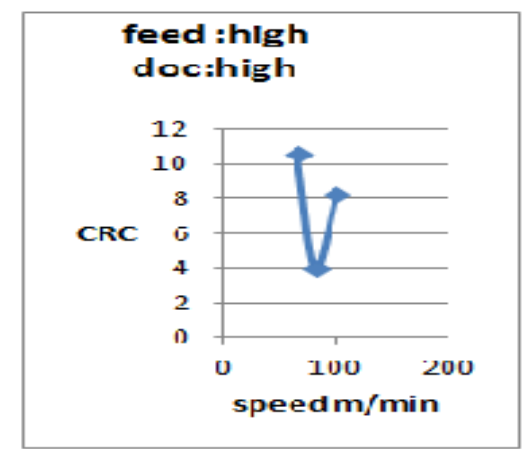

Fig. 1 CRC variation with speed at high feed and high d.o.c. (Experimental).

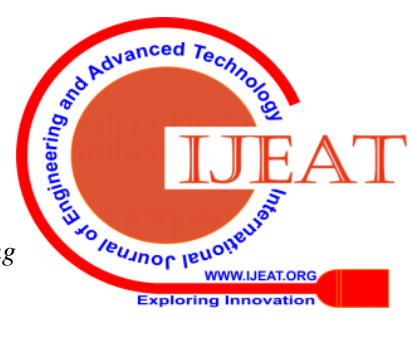




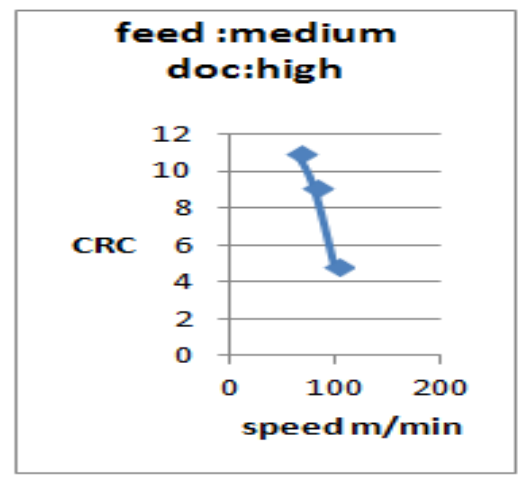

Fig. 2 CRC variation with speed at medium feed and high

d.o.c. (Experimental).

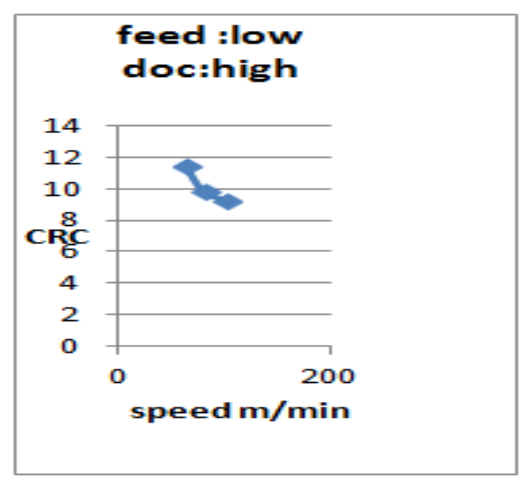

Fig. 3 CRC variation with speed at low feed and high

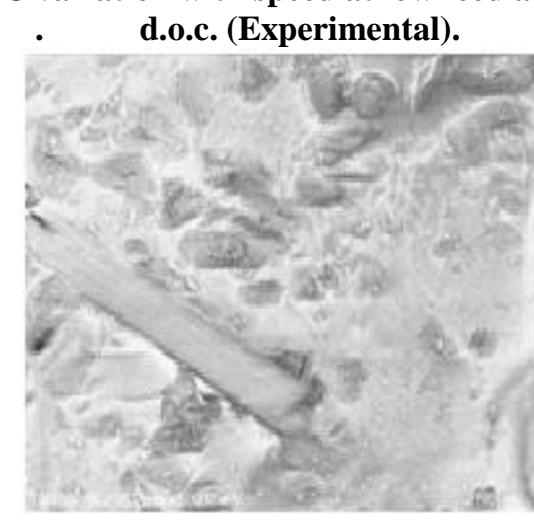

(a) $\mathrm{X500}$

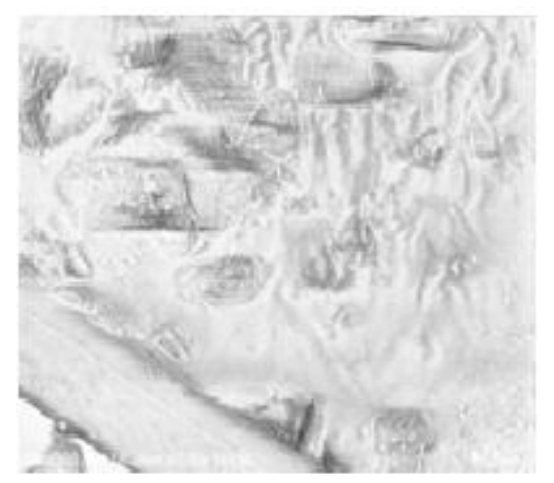

(b) $\mathrm{X1000}$

Fig. 4 Undersurface of chip at low speed (SEM).

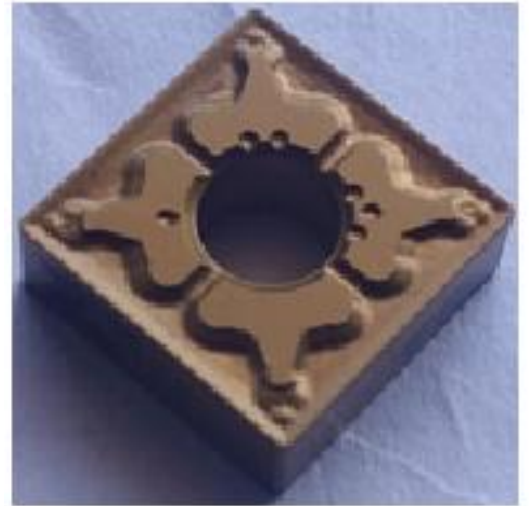

Fig. 5 Tungaloy made carbide insert having chip breaking shape.

In Fig. 6, chip photographs are arranged according to the following sequence:

$$
\begin{aligned}
& 1: \mathrm{v}=-1, \mathrm{f}=-1, \mathrm{~d}=-1 / / \quad 2: \mathrm{v}=-1, \mathrm{f}=-1, \mathrm{~d}=-0 / / \quad 3: \mathrm{v}=-1 . \mathrm{f}=- \\
& 1, \mathrm{~d}=1 / / \quad 4: \mathrm{v}=-1, \mathrm{f}=0, \mathrm{~d}=-1 / / \quad 5: \mathrm{v}=-1, \mathrm{f}=0, \mathrm{~d}=0 / / \quad 6: \mathrm{v}=- \\
& 1, \mathrm{f}=0, \mathrm{~d}=1 / / \quad 7: \mathrm{v}=-1, \mathrm{f}=1, \mathrm{~d}=-1 / / \quad 8: \mathrm{v}=-1, \mathrm{f}=1, \mathrm{~d}=0 / / \\
& 9: \mathrm{v}=-1, \mathrm{f}=1, \mathrm{~d}=1
\end{aligned}
$$
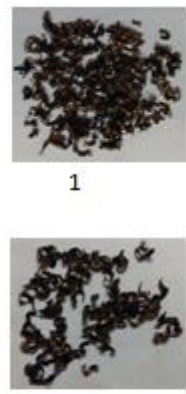

4

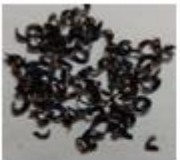

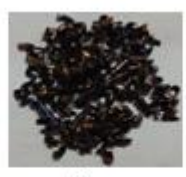

2

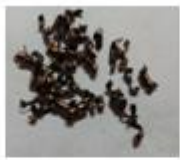

5

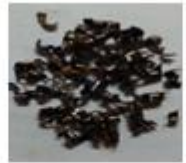

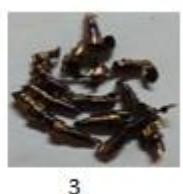

3

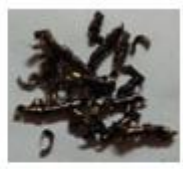

6

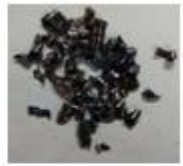

Fig. 6 Chips produced by carbide insert having chip breaking design.

As the speed increases, the CRC reduces because of predominating strain rate hardening of the work material which is evident in Fig. 2 and Fig. 3. No evidence of thermal softening was found at the under surface of the chip at higher speed during SEM examination. This observation supports the strain rate hardening effect at this cutting condition. This can be seen in Fig 7 .

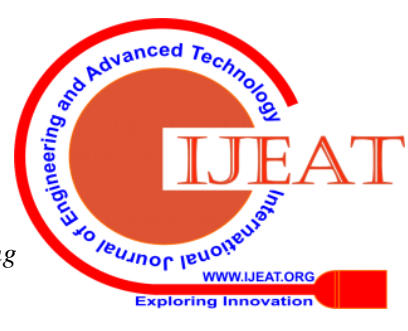




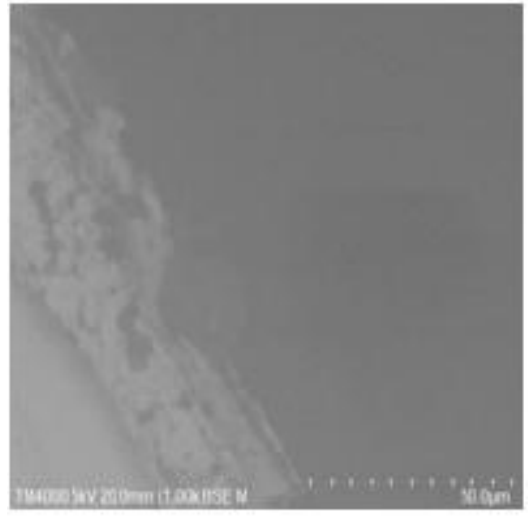

Fig. 7 Undersurface of chip at high speed (SEM). X2000

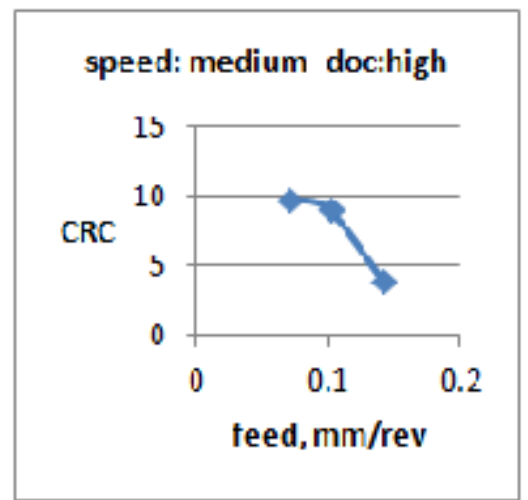

Fig. 8 Variation of CRC with feed at medium speed and high d.o.c. (Experimental).

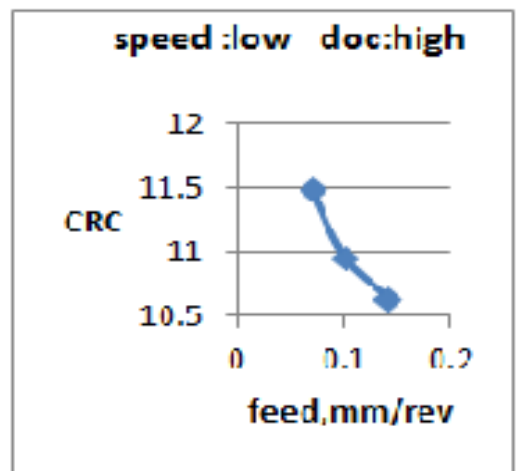

Fig. 9 Variation of CRC with feed at low speed and high d.o.c. (Experimental).

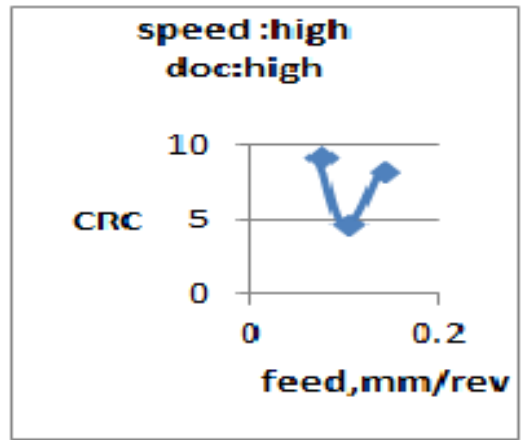

Fig.10 Variation of CRC with feed at high speed and high d.o.c. (Experimental).
Increase of feed at medium and low speed and high d.o.c reduces the CRC. At high feed, the CRC reduces mainly because of strain hardening of the work material as can be seen in Fig. 8 and Fig 9. At high speed and high d.o.c, strain hardening occurs at medium feed to reduce the value of CRC which is evident in Fig. 10. Increase in d.o.c at high and low feed and at high speed is to increase the CRC through thermal softening effect as evident in Fig. 11 and Fig. 12. At medium feed and high speed, strain hardening occurs at high doc causing lower CRC. This can be seen in Fig. 13.

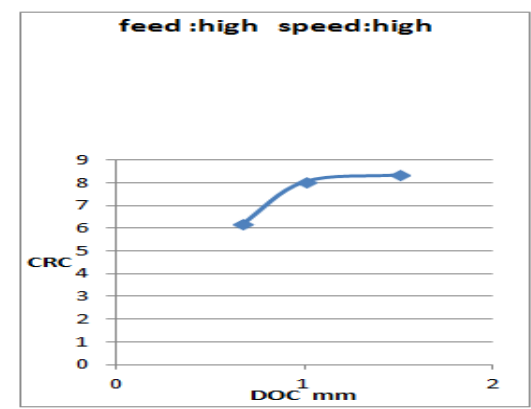

Fig. 11 Variation of CRC with d.o.c. at high feed and high speed. (Experimental).

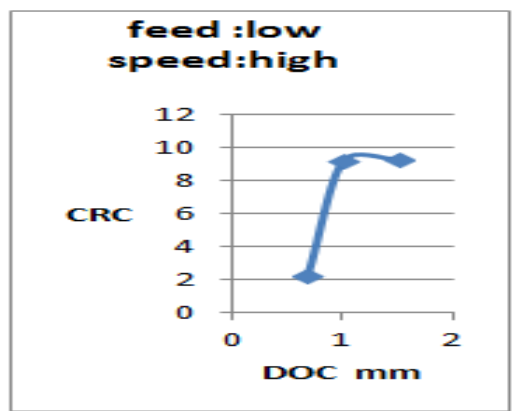

Fig. 12 Variation of CRC with d.o.c at low feed and high speed. (Experimental).

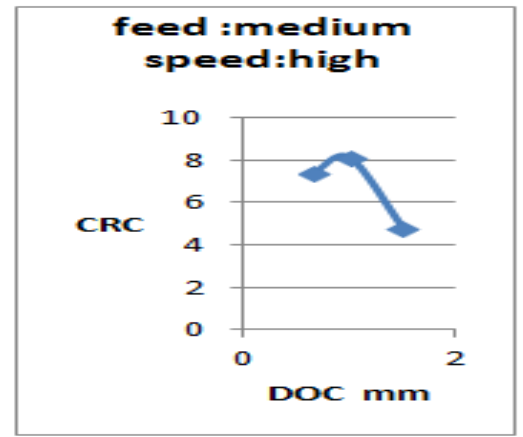

Fig. 13 Variation of CRC with d.o.c at medium feed and high speed. (Experimental).

B. Surface roughness model $\left(R_{a}\right)$

Equation (6) is the surface roughness equation obtained by $3^{3}$ factorial design.

Published By:

Blue Eyes Intelligence Engineering

\& Sciences Publication

C Copyright: All rights reserved.

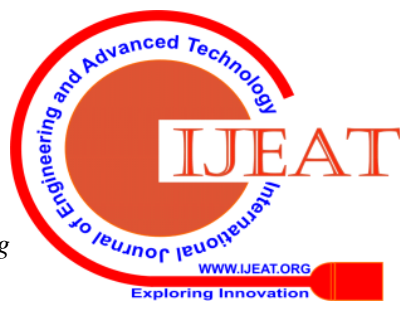


$\mathrm{Ra}_{\mathrm{h} 13}=1.5531+0.0512 \mathrm{x}_{1}-0.2177 \mathrm{x}_{2}-0.1147 \mathrm{x}_{3}-$ $0.2383 \mathrm{x}_{1}{ }^{2}+0.1824 \mathrm{x}_{3}{ }^{2}-0.0301 \mathrm{x}_{3}{ }^{2}-0.0104 \mathrm{x}_{1} \mathrm{x}_{2}-$ $0.0197 x_{1} x_{3}+0.1829 x_{1} x_{2}$

Where, $\mathrm{x}_{1}, \mathrm{x}_{2}$ and $\mathrm{x}_{3}$ are levels of speed, feed and d.o.c

Deviation of predicted data from experimental data is shown in Fig. 14.

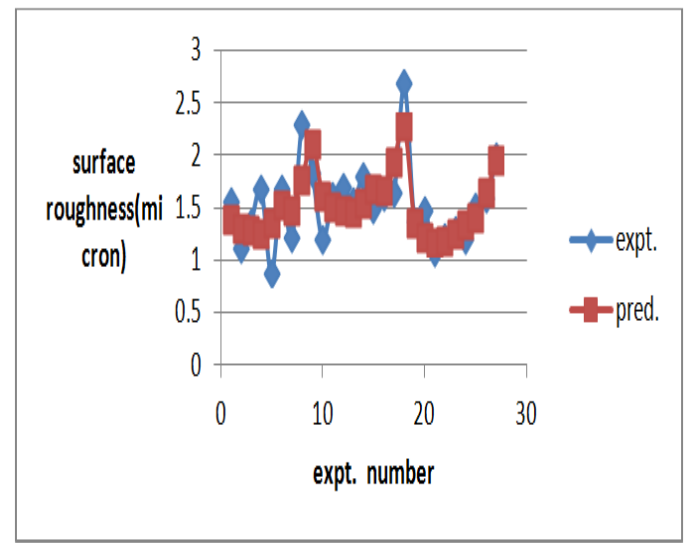

Fig 14 Variation between experimental and predicted data.

Analysis of variance through MATLAB programming yielded the data as shown in Table 2 .

Table 2 AOV table

\begin{tabular}{|c|c|c|c|c|}
\hline Source & d.o.f & s .s & m s & F ratio \\
\hline Regression & 9 & 2.0903 & 0.2323 & 2.3906 \\
\hline Error & 17 & 1.6517 & 0.0972 & \\
\hline Total & 26 & & & \\
\hline
\end{tabular}

It is seen from analysis of variance (AOV) Table 2 that $\mathrm{F}$ ratio obtained is 2.3906. This obtained $\mathrm{F}$ ratio is greater than available F ratio (2.0284) in statistical table .

So, $F_{9,17,0.90}$ (obtained) $>F_{9,17,0.90}$ (from statistical table ) . This shows that the surface roughness model (equation. 6) can be accepted for discussion

\section{Surface roughness at lowest cutting speed}

Overall surface roughness values are in the average range as can be seen in Fig. 15. Strain hardening followed by thermal softening causes Ra values at average range. This finding is in agreement with the thermal softening effect as reported earlier . However, as the feed increases, Ra value decreases causing improvement in surface roughness. This is in agreement with the previous finding as seen in Fig. 8 and Fig. 9. Increased feed is seemed to induce strain hardening at this stage.

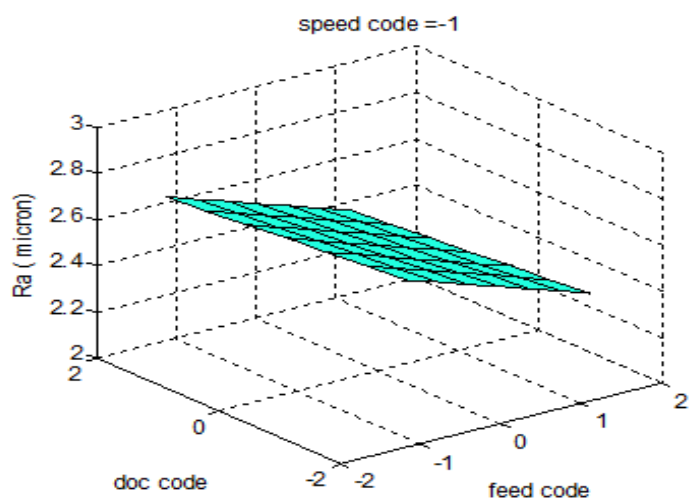

Fig. 15 Variation of surface roughness with feed and d.o.c at low speed.

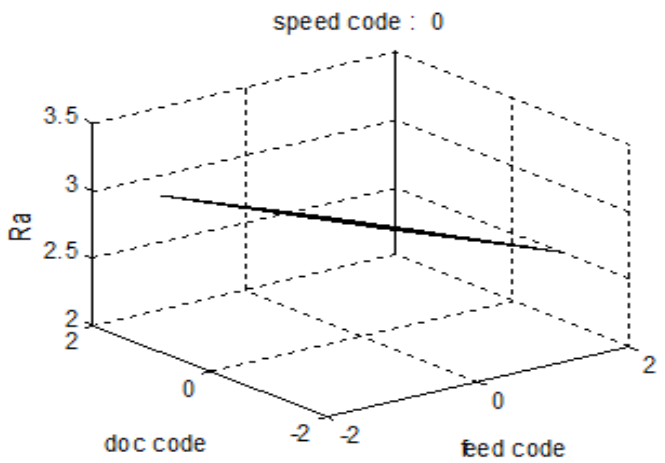

Fig. 16 Variation of surface roughness with feed and d.o.c at medium speed.

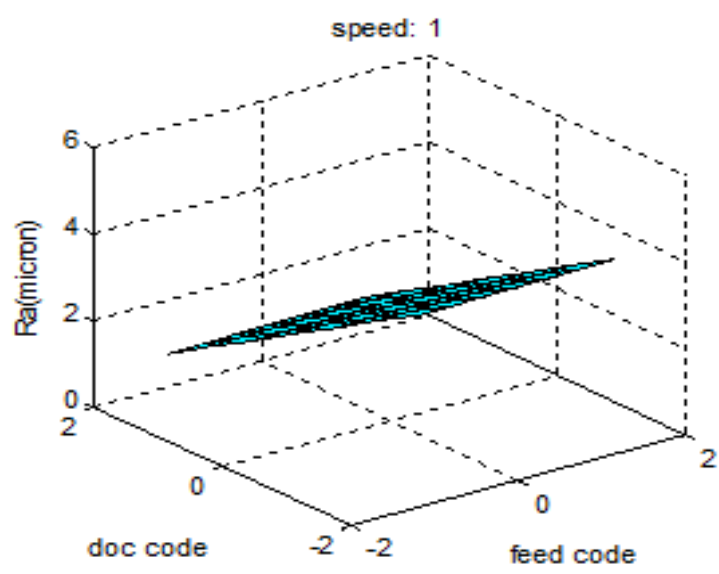

Fig. 17 Variation of surface roughness with feed and d.o.c at high speed.

\section{Surface roughness at medium cutting speed}

Overall surface roughness values are in the average range. Thermal softening at this cutting speed is seemed to increase Ra values impairing surface quality. Ra value improves with increase in feed mainly because of strain hardening and subsequent brittleness transition of the work material (Fig. 16).

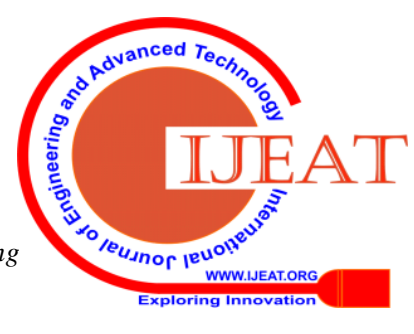




\section{E. Surface roughness at high cutting speed}

At higher speed, overall $\mathrm{Ra}$ values are comparatively smaller. This is due to strain rate hardening at higher speed causing brittleness transition of the work material. This finding further supports the same as reported earlier in Fig. 2 and Fig. 3. Increase in d.o.c is seen to improve the surface finish (Fig. 17). This finding is also in agreement with the previous observation as seen in Fig. 13. Brittleness transition due to strain rate hardening is seemed to be aggravated to cause better surface finish at higher d.o.c.

\section{CONCLUSIONS}

At low speed and low feed, poorer surface finish is resulted mainly because of thermal softening effect. At low speed, variation in d.o.c. has negligible influence on surface finish. Better surface quality can be achieved at high speed machining preferably at higher d.o.c. and low feed. This is attributed to strain rate hardening at high speed. Feed variation does not cause any influence on surface finish at high speed.

\section{ACKNOWLEDGMENT}

The authors sincerely and gratefully acknowledge the assistance provided by IIT Kharagpur for using the 3D optical surface profilometer for surface roughness measurement.

\section{REFERENCES}

1. C.E.P. Robert, J.A.P. Jana, S Marek, M. Petr, V Jan, H Martal, and A. Czan, "Surface roughness after machining and influence of feed rate on process", Key Engineering Materials , volume 581, pp341-347, 2014.

2. A. Singh, H. Singh and R. Kumar, "Review on effects of process parameters in hard turning of steels", International Journal for Innovative Research in Science and Technology, pp2349-6010, 2016.

3. T. Ozel, T. K. Hsu and E. Zeren, "Effects of cutting edge geometry, workpiece hardness, feed rate and cutting speed on surface roughness and forces in finish turning of hardened AISI H13 steel". The International Journal of Advanced Manufacturing Technology, 25, pp 262-269, 2005

4. R. Ferreiral, J. Rehor, C. H. Lauro, D. Caroul and J.P. Davim, “ Analysis of the hard turning of AISI H13 steel with ceramic tools based on tool geometry, surface roughness, tool wear and their relation", 2016.

\section{AUTHORS PROFILE}

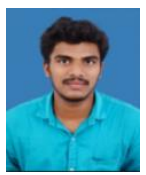

Anoop $\mathbf{K}$ is presently pursuing $\mathbf{M}$ Tech in design and manufacturing at N.I.T. Silchar In the department of mechanical engineering.

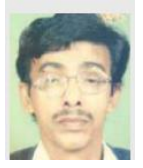

Dr. Kalyan Chakraborty is serving at N.I.T. Silchar in the department of mechanical engineering as Associate Professor

\section{APPENDIX}

Measured surface roughness values.

\begin{tabular}{|c|c|c|c|c|}
\hline \multirow{2}{*}{$\begin{array}{c}\text { Serial } \\
\text { No }\end{array}$} & \multicolumn{3}{|c|}{ Assigned codes } & \multirow{2}{*}{$\begin{array}{c}\text { Surface } \\
\text { roughness } \\
\left(\mathrm{R}_{\mathrm{a}}\right)(\boldsymbol{\mu m})\end{array}$} \\
\hline & $\mathbf{v}$ & $\mathbf{f}$ & d & \\
\hline 1 & 1 & 1 & 1 & 1.558 \\
\hline 2 & 1 & 1 & 0 & 1.109 \\
\hline 3 & 1 & 1 & -1 & 1.352 \\
\hline 4 & 1 & 0 & 1 & 1.68 \\
\hline 5 & 1 & 0 & 0 & 0.872 \\
\hline 6 & 1 & 0 & -1 & 1.675 \\
\hline 7 & 1 & -1 & 1 & 1.206 \\
\hline 8 & 1 & -1 & 0 & 2.288 \\
\hline 9 & 1 & -1 & -1 & 1.829 \\
\hline 10 & 0 & 1 & 1 & 1.202 \\
\hline 11 & 0 & 1 & 0 & 1.603 \\
\hline 12 & 0 & 1 & -1 & 1.688 \\
\hline 13 & 0 & 0 & 1 & 1.56 \\
\hline 14 & 0 & 0 & 0 & 1.793 \\
\hline 15 & 0 & 0 & -1 & 1.478 \\
\hline 16 & 0 & -1 & 1 & 1.604 \\
\hline 17 & 0 & -1 & 0 & 1.648 \\
\hline 18 & 0 & $\begin{array}{l}-1 \\
\end{array}$ & -1 & 2.677 \\
\hline 19 & -1 & 1 & 1 & 1.363 \\
\hline 20 & -1 & 1 & 0 & 1.464 \\
\hline 21 & -1 & 1 & -1 & 1.072 \\
\hline 22 & -1 & 0 & 1 & 1.208 \\
\hline 23 & -1 & 0 & 0 & 1.276 \\
\hline 24 & -1 & 0 & -1 & 1.187 \\
\hline 25 & -1 & -1 & 1 & 1.5 \\
\hline 26 & -1 & -1 & 0 & 1.59 \\
\hline 27 & -1 & -1 & -1 & 1.988 \\
\hline
\end{tabular}

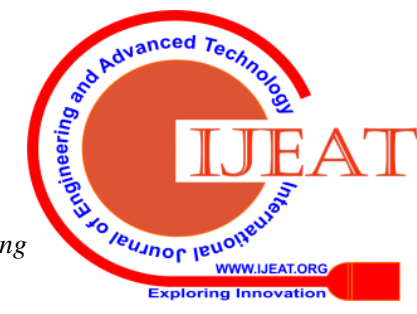

